\title{
Genetic Profile and Clinical Implications of PDGFRB Fusion in Adult B-Cell Acute Lymphoblastic Leukemia: A Retrospective Analysis
}

Guofa Xu

Soochow University Affiliated No 1 People's Hospital: First Affiliated Hospital of Soochow University https://orcid.org/0000-0003-4945-7274

Xie-bing Bao

Soochow University Affiliated No 1 People's Hospital: First Affiliated Hospital of Soochow University

Li-min Liu

Soochow University Affiliated No 1 People's Hospital: First Affiliated Hospital of Soochow University

Man Wang

Soochow University Affiliated No 1 People's Hospital: First Affiliated Hospital of Soochow University

Zhi-bo Zhang

Soochow University Affiliated No 1 People's Hospital: First Affiliated Hospital of Soochow University

Zhao Zeng

Soochow University Affiliated No 1 People's Hospital: First Affiliated Hospital of Soochow University

Jun-dan Xie

Soochow University Affiliated No 1 People's Hospital: First Affiliated Hospital of Soochow University

Hui-ying Qiu ( $\sim$ qiuhuiying8303@suda.edu.cn )

Su-ning Chen

Soochow University Affiliated No 1 Peoplel's Hospital: First Affiliated Hospital of Soochow University

De-Pei Wu

Soochow University Affiliated No 1 People's Hospital: First Affiliated Hospital of Soochow University

\section{Research}

Keywords: Acute lymphoblastic leukemia, PDGFRB fusion, Hematopoietic stem cell transplantation, Chimeric antigen receptor T cell, Philadelphia-like

Posted Date: April 6th, 2021

DOl: https://doi.org/10.21203/rs.3.rs-389583/v1

License: (c) (i) This work is licensed under a Creative Commons Attribution 4.0 International License. Read Full License 


\section{Abstract}

Background:To investigate the pathogenesis, genetic changes, treatment and prognosis of adult B-cell acute lymphoblastic leukemia (B-ALL) with plateletderived growth factor receptor $\mathrm{B}(P D G F R B)$ fusion.

Method冈Clinical characteristics, treatment process and prognosis of 7 adult B-ALL patients with PDGFRB fusion were presented respectively, and the PDGFRB fusion was confirmed by fluorescence in situ hybridization, RNA sequencing and Polymerase Chain Reaction.

Results: 7 adult B-ALL patients with PDGFRB fusion were presented respectively. There were 5 males and 2 females, with a median age of 21 (range, 17-39) years and a median white blood cell count of 7.85 (range, 2.30-111.25) $\times 10^{\wedge} 9 / \mathrm{L}$. The fusion partners were EBF1, SMIM3 and TERF2. Three of 7 cases received tyrosine kinase inhibitor (TKI) targeted therapy, and 4 of 7 cases received chimeric antigen receptor T -cell (CAR-T) therapy. A total of $6(85.71 \%)$ cases underwent haploid hematopoietic stem cell transplantation (Haplo-HSCT). Overall response rate was $71.43 \%$ (4/7), and the common adverse reactions during induction were febrile neutropenia and nausea. Seventy-five percent (3/4) and 100\% (6/6) of patients were minimal residual disease negative after CAR-T and Haplo-HSCT. To the last follow-up, 2 of 7 cases relapsed in 2 and 7 months after remission, respectively, and the estimated 36 months of Event-free survival and Overall survival was $75.0 \%$ and $66.7 \%$.

Conclusions: intensive therapy combined with CAR-T or TKI is needed to achieve deep remission, and sequential Haplo-HSCT may improve the prognosis of adult B-ALL with PDGFRB fusion.

\section{Background}

Disease progression remains a primary cause of mortality in B cell acute lymphoblastic leukemia (B-ALL), especially for Philadelphia-like (Ph-like) ALL, a highrisk subtype of B-ALL. ${ }^{1}$ Owning a similar gene expression profile of Philadelphia chromosome-positive (Ph+) ALL, Ph-like ALL is associated with poor prognosis. ${ }^{2}$ Allogeneic hematopoietic stem cell transplantation (allo-HSCT) was recommend and may improved this poor outcome. ${ }^{3}$ Fusion of platelet-derived growth factor receptor $\mathrm{B}(P D G F R B)$ has been emphasized in myeloproliterative neoplasms, and has become a therapeutic target of tyrosine kinase inhibitor (TKI). ${ }^{4}$ However, belonging to the ABL-class of fusion kinase category of Ph-like B-ALL, the fusion oncogene of $P D G F R B$ are rarely reported in B-ALL. ${ }^{5} P D G F R B$ rearrangement in conventional karyotype examination is prone to low detection rate and missed diagnosis, ${ }^{6}$ and a rather proportion of $\mathrm{B}-\mathrm{ALL}$ with $P D G F R B$ rearrangement were refractory to conventional therapy. ${ }^{7}$ Given that patients with $P D G F R B$ fusions are amenable to targeted therapy of TKI, ${ }^{8}$ it is necessary to identify these patients by using a comprehensive screening strategy. To provide a better comprehension of the clinical and pathological features, we performed a retrospective observational study in 7 cases of B-ALL with PDGFRB fusion in the First Affiliated Hospital of Soochow University.

\section{Method}

\section{Patients and Study design}

This was a retrospective, observational and descriptive study in the First Affiliated Hospital of Soochow University, which was approved by Ethics Committee of hospital, and informed consent form was provided by all patients. From 2015 to 2020, a total of 423 patients were diagnosed as Philadelphia chromosomenegative (Ph-) B-ALL in our center. 7 cases of which (1.6\%) were found with PDGFRB fusion, and included in our study. The diagnosis of ALL with PDGFRB fusion was based on morphology, immunotyping, chromosome karyotype, molecular genetics and detection of somatic mutation (illumina nextseq550). Polymerase Chain Reaction (PCR), fluorescence in situ hybridization (FISH) and RNA sequencing (RNA seq, novaseq 6000) were integrated as the methods for testing PDGFRB fusion.

\section{Treatment protocols}

Induction chemotherapy: IVP (Idarubicin, Vincristine and Prednisone)-like regimen, such as VILP (L: L-Asparaginasum/pegaspargase), VDCP (D: doxorubicin, C: Cyclophosphamide), CIVP and VDLP was executed as the treatment protocols of induction therapy. Only one case (case 3 ) received the regimen of hyperfractionated cyclophosphamide, vincristine, doxorubicin, and dexamethasone (Hyper-CVAD)-A, ${ }^{9}$ and another case (case 5) took Dasatinib orally for inductive treatment (Table 2). The minimal residual disease (MRD) was analyzed in the bone marrow by flow cytometry (Beckman Coulter Ireland, Navios, Flow 10-color antibody panels). Consolidation regimen: Consolidation chemotherapy was based on high-dose methotrexate (MTX) and cytarabine (Ara-C), ${ }^{10}$ and 3 cases were combined with TKI therapy (Table 2). Chimeric antigen receptor-modified T cell (CAR-T) therapy: CAR-T cells were derived from autologous lymphocyte. Production of CAR-T cell was described in detail according to the previous report. ${ }^{11}$ Allogeneic hematopoietic stem cell transplantation (AlloHSCT): The conditioning regimen for patients received Allo-HSCT was modified BUCY (semustine, cytarabine, busulfan, and cyclophosphamide, BuCy). ${ }^{12}$ All patients received the transfusion support of umbilical cord blood (UCB) pre-transplantation. ${ }^{13}$ Cyclosporin A, short-term methotrexate, and mycophenolate mofetil were used for graft-versus-host disease (GvHD) prophylaxis. ${ }^{14}$ Moreover, Anti-Thymocyte Globulin (ATG, Genzyme, Cambridge, MA, USA) was also administrated in vivo at $2.5 \mathrm{mg} / \mathrm{kg}$ on days -5 to -2 for preventing GvHD after haploidentical allo-HSCT.

\section{Definitions and evaluations}

Definition: Complete remission (CR), partial remission (PR), and relapsed disease were defined according to 2017 ELN recommendations. ${ }^{15}$ Overall response rate (ORR) was defined as (CR + PR)/ (all of the patients). Negativity or remission of MRD was defined as a level of MRD lower than 0.0001 . CR without MRD (CRMRD-) was defined as CR with negativity by multiparametric flow cytometry (MFC). CR with MRD (CRMRD+) was defined as CR with positivity by MFC. 
Cytokine Release Syndrome (CRS) and Neurologic Toxicity was graded respectively according to the consensus. ${ }^{16}$ The methods of diagnosis and treatment for acute GVHD (aGVHD) and chronic GVHD (cGVHD) were previously described in detail. ${ }^{17,18,19}$

\section{Results}

\section{Patients' characteristics}

The characteristics of 7 patients with PDGFRB fusion were showed in Table 1, including 5 males and 2 females, with a median onset age of 21 (range, 17 to 39) years. There were 5 cases of initial diagnosis and other 2 cases of recurrence ALL. The median white blood cell (WBC) count at diagnosis was 7.85 (range, 2.3 to 111.25$) \times 10^{\wedge} 9 / \mathrm{L}$, and median platelet count was 51 (range, 28 to 191) $\times 10^{\wedge} 9 / \mathrm{L}$. The fusion partners were EBF1 $(n=4), \operatorname{SMIM} 3(n=1)$, TERF2 ( $\left.n=1\right)$ and only 1 case with a unknown partner gene. For patients with EBF1-PDGFRB fusion, corresponding mutations were found with $B C O R L 1$ germline mutation, and somatic mutation of PAX5 and RUNX1, respectively. Case 3 was combined with SMIM3/PDGFRB fusion and TP53 somatic mutation. 4 of 7 cases showed anemia and most of patients (6/7) presented as normal karyotype at diagnosis. No eosinophils were found in bone marrow morphology, and there was no 5q31-33 rearrangement in karyotype in all patients (Table 1).

Table 1. Clinical data for PDGFRB fusion patients

\begin{tabular}{|c|c|c|c|c|c|c|c|c|c|c|c|c|}
\hline & Sex & $\begin{array}{l}\text { onset } \\
\text { age } \\
\text { (y) }\end{array}$ & $\begin{array}{l}\text { Diagnostic } \\
\text { state }\end{array}$ & $W B C \times 10^{\wedge} 9$ & $\mathrm{HB}(\mathrm{g} / \mathrm{L})$ & $\mathrm{PLT} \times 10^{\wedge} 9$ & $\begin{array}{l}\text { BM: } \\
\text { blasts\% }\end{array}$ & $\begin{array}{l}\text { FCM: } \\
\text { blasts\% }\end{array}$ & Method & Fusion type & $\begin{array}{l}\text { mutant } \\
\text { gene }\end{array}$ & chromosome \\
\hline 1 & $\mathrm{~F}$ & 17 & preliminary & 7.9 & 70 & 45 & 51.5 & 86.3 & PCR & $E B F 1 / P D G F R B$ & $\begin{array}{l}\text { BCORL } 1 \\
\text { Germline } \\
\text { mutation }\end{array}$ & normal \\
\hline 2 & $M$ & 39 & relapse & 47.3 & 143 & 28 & 90.0 & 90.9 & $\begin{array}{l}\text { PCRI } \\
\text { FISH }\end{array}$ & $E B F 1 / P D G F R B$ & $\begin{array}{l}\text { PAX5 } \\
\text { mutation }\end{array}$ & normal \\
\hline 3 & $M$ & 21 & preliminary & 2.3 & 76 & 45 & 87.5 & 87.8 & $\begin{array}{l}\text { RNA- } \\
\text { seq }\end{array}$ & SMIM3/PDGFRB & $\begin{array}{l}\text { TP53 } \\
\text { mutation }\end{array}$ & normal \\
\hline 4 & $M$ & 21 & preliminary & 11.3 & 120 & 185 & 52.0 & 71.8 & $\begin{array}{l}\text { RNA- } \\
\text { seq }\end{array}$ & $E B F 1 / P D G F R B$ & $\begin{array}{l}\text { RUNX1 } \\
\text { mutation }\end{array}$ & abnormal* \\
\hline 5 & $\mathrm{~F}$ & 26 & preliminary & 111.3 & 56 & 51 & 90.0 & 76.2 & $\begin{array}{l}\text { RNA- } \\
\text { seq }\end{array}$ & TERF2/PDGFRB & negative & $\begin{array}{l}\text { no } \\
\text { metaphase }\end{array}$ \\
\hline 6 & $M$ & 20 & preliminary & 2.4 & 73 & 172 & 91.5 & 55.7 & PCR & $E B F 1 / P D G F R B$ & NK & normal \\
\hline 7 & $M$ & 28 & relapse & 4.6 & 131 & 191 & 6.0 & 55.7 & $\mathrm{FISH}$ & PDGFRB fusion & $\begin{array}{l}I K Z F 1-I K 6 \\
\text { transcribed } \\
\text { isomers }\end{array}$ & normal \\
\hline
\end{tabular}

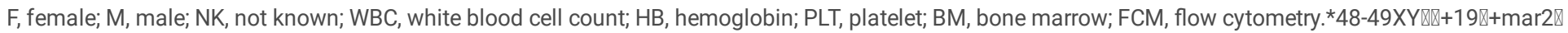
inc[cp2]/46,XY[8]

\section{Response and Adverse Events of Induction Therapy}

Of 7 patients, the overall rate of early response was $42.86 \%$ (3/7, Table 2). To 33 days after induction therapy, ORR was $71.43 \%$ ( 3 cases with CRMRD-; one case with CR and unknown MRD status), the CR rate at the end of induction therapy was only $57.14 \%$ (4/7). For case 1,4 and 5 without CR after initial induction therapy, reached CR after plus chemotherapy, CAR-T, dasatinib plus chemotherapy, respectively. The common adverse events during induction chemotherapy were febrile neutropenia ( $2 / 7,28.57 \%)$, oral mucosal hemorrhage (1/7,14.29\%), nausea (3/7,42.86\%), and vomiting (1/7,14.29\%). No patients died from induction chemotherapy. The median time of CR was 33 (range, 7 to 85 ) days, and the median time of MRD negative was 33 (range, 18 to 139 ) days.

\section{Consolidation, Relapse and Survival}

Three cases undertook a comprehensive therapy combined with TKI; TKI was administrated after CR for case 1, after MRD- for case 2, and in the middle of induction chemotherapy for case 3 , respectively. Four cases received CAR-T therapy ( 2 for eliminating MRD, and 2 for re-induction therapy) and 6 cases underwent allo-HSCT from haploid-related donors. The recurrence rate was $28.57 \%$ (2/7). Case 2 and 7 experienced disease recurrence before allo-HSCT, with 2 and 7 months from CR to relapse, respectively. Both cases 3 and 6 were treated with Hyper CVAD A/B in consolidation therapy. The patients were followed up until January 30, 2021, and a median follow-up time was 29 (range, 7 to 72) months. Case 7 died of infection after allo-HSCT, with a persistent positivity of MRD. The estimated 36 months of Event-free survival (EFS) and Overall survival (OS) was $75.0 \%$ and 66.7\%. (Table 2, Figure 1, Figure 2)

Table 2. therapy and survival data for PDGFRB fusion patients 


\begin{tabular}{|c|c|c|c|c|c|c|c|c|c|c|}
\hline & Induction & $14 d$ & $33 d$ & $\begin{array}{l}\text { Time of CR } \\
\text { (d) }\end{array}$ & $\begin{array}{l}\text { Time of MRD- } \\
\text { (d) }\end{array}$ & $\begin{array}{l}\text { targeted } \\
\text { therapy }\end{array}$ & $\begin{array}{l}\text { CAR- } \\
\mathrm{T}\end{array}$ & HSCT & $\begin{array}{l}\text { Months to } \\
\text { Relapse(m) }\end{array}$ & Status(moths) \\
\hline 1 & VILP & NR & NR & 85 & never & Imatinib & Yes & No & NA & loss to follow-up \\
\hline 2 & VDCP & PR & $\mathrm{CR}_{\mathrm{MRD}-}$ & 33 & 33 & Dasatinib & Yes & Yes & 2 & Alive (16) \\
\hline 3 & Hyper-CVAD A & $\mathrm{CR}_{\mathrm{MRD}-}$ & $\mathrm{CR}_{\mathrm{MRD}-}$ & 7 & 18 & No & No & Yes & NA & Alive (29) \\
\hline 4 & VILP & NR & NR & 77 & 110 & No & Yes & Yes & NA & Alive (37) \\
\hline 5 & $\begin{array}{l}\text { CIVP+ } \\
\text { Dasatinib }\end{array}$ & NR & PR & 61 & 139 & Dasatinib & Yes & Yes & NA & Alive (7) \\
\hline 6 & VILP & PR & $\mathrm{CR}_{\mathrm{MRD}-}$ & 29 & 29 & No & No & Yes & NA & Alive (72) \\
\hline 7 & VDLP & NK & $\mathrm{CR}$ & 33 & NK & No & No & Yes & 7 & $\begin{array}{l}\text { Died of infection } \\
\text { (32) }\end{array}$ \\
\hline
\end{tabular}

V, Vincristine; D, daunorubicin; L, L-asparaginase/pegaspargase/Pegaspargase; P, prednison; C, cyclophosphamide; I, Idarubicin; NR, non-remission; NK, not known

\section{Treatment of CART}

A total of 4 patients were infused with CAR-T cells for re-induction or eliminating MRD (Figure 1, Table 3). Case 2 was successfully infused with antiCD19CD22 $\left(5^{\star} 10^{\wedge} 6 / \mathrm{kg}\right)$, while other 3 patients (case $\left.1,4,5\right)$ received the therapy of anti-CD $19\left(5^{\star} 10^{\wedge} 6 / \mathrm{kg}\right)$ CAR-T cells. Grade 2 of CRS appeared in 2 of 4 patients. Three cases $(3 / 4,75 \%)$ achieved MRD remission after CAR-T treatment. A persistent positivity of MRD was presented in case 1 , with a 0.001 level of MRD. Bridging transplantation was performed in case 2, 4, 5 after CAR-T treatment. Allo-HSCT was not performed because there was no donor available for case 1 (Table 3).

Table 3. CAR-T data for PDGFRB fusion patients

\begin{tabular}{|c|c|c|c|c|c|c|c|c|c|}
\hline & $\begin{array}{l}\text { Relapse before } \\
\text { CART }\end{array}$ & $\begin{array}{l}\text { Status before } \\
\text { CART }\end{array}$ & $\begin{array}{l}\text { Blasts before } \\
\text { FC\% }\end{array}$ & $\begin{array}{l}\text { CART } \\
\text { source }\end{array}$ & Target & $\begin{array}{l}\text { cell } \\
\text { quantity } \\
\times 10^{\wedge} 6 / \mathrm{kg}\end{array}$ & CRS & $\begin{array}{l}\text { therapeutic } \\
\text { effect }\end{array}$ & $\begin{array}{l}\text { Bridging } \\
\text { transplantation }\end{array}$ \\
\hline 1 & No & $\mathrm{CR}_{\mathrm{MRD}+}$ & 0 & Autologous & CD19 & 5 & 2 & $\mathrm{CR}_{\mathrm{MRD}+}$ & 0 \\
\hline 2 & Yes & NR & 37 & Autologous & CD19CD22 & 10 & 2 & $\mathrm{CR}_{\text {MRD- }}$ & 1 \\
\hline 4 & No & PR & 7 & Autologous & CD19 & 5 & 0 & $\mathrm{CR}_{\mathrm{MRD}-}$ & 1 \\
\hline 5 & No & $\mathrm{CR}_{\mathrm{MRD}+}$ & 0 & Autologous & CD19 & 5 & 0 & $\mathrm{CR}_{\mathrm{MRD}-}$ & 1 \\
\hline
\end{tabular}

\section{Allo-HSCT}

A total of 6 patients underwent Allo-HSCT from haploid-related donors (Haplo-HSCT). A total of 3 cases underwent CART bridging transplantation, and case 2 received CAR-T therapy as re-induction therapy before transplantation. Case 7 underwent Hyper-CVAD, VDCP, VTCP, AAG (cytarabinoside + acracycin + G-CSF) regimen and did not achieve $\mathrm{CR}$, and then received Salvage transplantation. The median time was 5.5 (range, 4-16) months from diagnosis to transplant. Side effects were mainly for the mild skin GVHD (grade 1) and diarrhea. No cases have disease recurrence after transplantation. Table 4.

Table 4. Haplo-HSTC data for PDGFRB fusion patients

\begin{tabular}{|c|c|c|c|c|c|c|c|c|c|c|c|c|}
\hline & $\begin{array}{l}\text { CAR- } \\
T\end{array}$ & relapse & $\begin{array}{l}\text { Status } \\
\text { before } \\
\text { HSCT }\end{array}$ & $\begin{array}{l}\text { Diagnosis } \\
\text { to HSCT } \\
\text { time }(\mathrm{m})\end{array}$ & $\begin{array}{l}\text { stem cell } \\
\text { source }\end{array}$ & $\begin{array}{l}\text { MNC } \\
\left(10^{\wedge} 8 / \mathrm{Kg}\right)\end{array}$ & $\begin{array}{l}\text { CD34+ } \\
\left(10^{\wedge} 6 / \mathrm{Kg}\right)\end{array}$ & $\begin{array}{l}\text { Neutrophil } \\
\text { engraftment } \\
\text { (d) }\end{array}$ & $\begin{array}{l}\text { Platelet } \\
\text { engraftment } \\
\text { (d) }\end{array}$ & complication & $\begin{array}{l}\text { Post- } \\
\text { HSCT } \\
\text { MRD } \\
\text { level }\end{array}$ & $\begin{array}{l}\text { relap } \\
\text { of } \\
\text { post- } \\
\text { HSC1 }\end{array}$ \\
\hline 2 & Yes & Yes & CR2 ${ }_{\text {MRD- }}$ & 6 & $\mathrm{CB}+\mathrm{PB}$ & 7.05 & 2.97 & 11 & 12 & GVHD skin & $0 * 10 \mathrm{E}-4$ & No \\
\hline 3 & No & No & $\mathrm{CR} 1_{\mathrm{MRD}+}$ & 6 & $\mathrm{CB}+\mathrm{BM}$ & 3.3 & 1.518 & 11 & 13 & GVHD skin & $0 * 10 \mathrm{E}-4$ & No \\
\hline 4 & Yes & No & $\mathrm{CR} 1_{\mathrm{MRD}-}$ & 4 & $\mathrm{CB}+\mathrm{BM}+\mathrm{PB}$ & 11.48 & 3.77 & 12 & 13 & diarrhea & $\begin{array}{l}0.1 * 10 \mathrm{E}- \\
4\end{array}$ & No \\
\hline 5 & Yes & No & $\mathrm{CR} 1_{\mathrm{MRD}}$ & 5 & $\mathrm{CB}+\mathrm{PB}$ & 5.44 & 5.02 & 12 & 12 & No & $0 * 10 \mathrm{E}-4$ & No \\
\hline 6 & No & No & CR1 $1_{\text {MRD- }}$ & 5 & $\mathrm{CB}+\mathrm{BM}+\mathrm{PB}$ & 10.2 & 2.04 & 10 & 11 & No & $0 * 10 \mathrm{E}-4$ & No \\
\hline 7 & No & Yes & NR & 16 & $\mathrm{CB}+\mathrm{BM}$ & 9.48 & 2.75 & 12 & 12 & GVHD skin & $0 * 10 \mathrm{E}-4$ & No \\
\hline
\end{tabular}

$\mathrm{CB}$, cord blood; $\mathrm{BM}$, bone marrow; $\mathrm{PB}$, peripheral blood 


\section{Discussion}

The PDGFRB gene located at chromosome $5 q 32 / 5 q 33$ is a member of the receptor tyrosine kinase family. ${ }^{7,20}$ The occurrence of chromosomal microdeletions during PDGFRB fusion resulted in difficult identification and missed diagnosis in routine chromosome karyotype analysis, which was also confirmed by the fact that no abnormality of chromosome was found in 5 out of 7 patients in this study. PDGFRB fusions result in the synthesis of constitutively activated tyrosine kinase fusion proteins, usually associated with continuous cell proliferation. ${ }^{21}$ Expression of PDGFRB fusions resulted in cytokine-independent proliferation and activation of phosphorylated STAT5. ${ }^{5}$ Cell lines and human leukemic cells expressing PDGFRB fusions were sensitive in vitro to dasatinib. ${ }^{5}$ Several signalling cascades, including the Ras/mitogen-activated protein kinase, phosphatidylinositol 3'-kinase and phospholipase-ypathways, are key downstream mediators of PDGFRB signalling. ${ }^{6}$ Haematopoietic neoplasms with PDGFRB fusions are very sensitive to tyrosine kinase inhibitors (TKIs). ${ }^{22}$

To date, 12 fusion partners of $P D G F R B$ have been reported in adult B-cell acute lymphoblastic leukemia, ${ }^{21,23-26}$ with $E B F 1-P D G F R B$ being the most common. ${ }^{7}$ EBF1-PDGFRB fusion accounts for $0.5 \%$ of B-cell precursor ALL and $2.7 \%$ of the B-other subtype. ${ }^{7}$ The EBF1 (EBF1) gene located at chromosome $5 q 33$, is a nuclear transcription factor required for normal B-lineage specification, commitment, and development. ${ }^{27}$ EBF1-PDGFRB fusion results in loss of EBF1 function, multimerization and autophosphorylation of the fusion protein, activation of STAT5 signaling, and gain of IL-7-independent cell proliferation. ${ }^{27}$ Deregulation and loss of EBF1 function is critically dependent on the nuclear export activity of the TM domain of PDGFRB. ${ }^{27}$ EBF1-PDGFRB synergizes with loss of IKAROS function in a fully penetrant B-ALL in vivo. ${ }^{27}$ In this study, fusion of EBF1-PDGFRB was confirmed in 4 of the 7 patients. Schwab et al. ${ }^{7}$ reported the results of 15 cases of pediatric ALL patients with positive EBF1-PDGFRB, with more females than males (11/15). In this study, there was a predominance of males (3/4), heterogeneity of disease between adults and children may need to be studied to confirm this phenomenon.

In this study, two novel fusion partners of PDGFRB were identified: SMIM3 and TERF2. In SMIM3-PDGFRB fusion, the SMIM3 breaking site was exon 1, with no coding promoter region and no coding fusion protein, while the $P D G F R B$ gene breaking site was exon 12 in the catalytic region of tyrosine kinase. Therefore, this case should not be classified as ph-like ALL. In TERF2-PDGFRB fusion, exon 1-8 of TERF2 gene is fused with exon 9-23 of PDGFRB gene, which loses the DNA binding domain of TERF2 gene and retains the tyrosine kinase domain of PDGFRB gene, which is expected to be involved in the proliferation and cell cycle differentiation of leukemia cells. We are studying and verifying the related functions of TERF2-PDGFRB fusion gene.

Hiroto Inaba and Charles G. Mullighan reported that the CR rate was approximately $98 \%$ in pediatric patients. ${ }^{28}$ However, the CR rate at the end of induction was only $57.14 \%$ in this group. The recurrence rate $(28.57 \%$ vs. $46.67 \%)$ of patients in this group were lower than literature reports, ${ }^{7}$ suggesting that intensive chemotherapy combined with other treatment methods (target therapy and CAR-T) may benefit the patients in this group. Case 3 with TP53 mutation was classified as high-risk but achieved early deep remission after receiving hyper-CVAD A regimen, which may support this assumption. Most of all, 6 of 7 cases in our group received allo-HSCT, which was still a curative therapeutic option for adults ALL patients with PDGFRB. For patients received targeted therapy (Case 1, 2 and 5), case 1 achieved CR soon after administrating the imatinib, however, MRD remained at 0.001 level for a long time even after CART therapy. Case 2 relapsed rapidly in 1.5 months after dasatinib administration. In case 5, the time-point of CR and CR $\mathrm{MRD}_{-}$was 61 and 139 days; even if CR was achieved after induction therapy, MRD remained positive and then turned negative after CAR-T therapy. As same as adult Ph + ALL, consisting of a TKI-based induction/consolidation 29,30 may be the suitable treatment for patients with PDGFRB fusion. It suggested that the targeted monotherapy is still inadequate for patients with PDGFRB fusion. Intensive therapy combined with CAR-T or TKI is needed to achieve deep remission for these patients. In our results, $75 \%$ (3/4) and $100 \%(6 / 6)$ of patients maintain MRD negative after CAR-T and Haplo-HSCT. It seem to be that sequential allo-HSCT after deep remission is expected to improve the prognosis of such patients, and we highly recommend the allo-HSCT as the consolidation if possible. Future studies in vitro and on large patients are very necessary to confirm this perspective, and this result may contribute to establish the current standard treatment paradigm for $P D G F R B$ fusion in adult B-cell ALL.

\section{Conclusion}

Our results suggested that intensive therapy combined with CAR-T or TKI is needed to achieve deep remission, and sequential allo-HSCT may improve the prognosis of these patients.

\section{Abbreviations}

B-cell acute lymphoblastic leukemia (B-ALL), platelet-derived growth factor receptor B (PDGFRB), tyrosine kinase inhibitor (TKI), chimeric antigen receptor T cell (CAR-T), haploid hematopoietic stem cell transplantation (Haplo-HSCT), minimal residual disease (MRD), Philadelphia-like (Ph-like), Philadelphia chromosome-positive (Ph+), Allogeneic hematopoietic stem cell transplantation (allo-HSCT), Philadelphia chromosome-negative (Ph-), Polymerase Chain Reaction (PCR), fluorescence in situ hybridization (FISH) and RNA sequencing (RNA seq), IVP (Idarubicin, Vincristine and Prednisone), Hyper-CVAD A, minimal residual disease (MRD), methotrexate (MTX) and cytarabine (Ara-C), semustine, cytarabine, busulfan, and cyclophosphamide (BuCy), umbilical cord blood (UCB), graft-versus-host disease (GvHD), Anti-Thymocyte Globulin (ATG), Complete remission (CR), partial remission (PR), Overall response rate (ORR), CR without MRD (CRMRD-), CR with MRD (CRMRD+), multiparametric flow cytometry (MFC),Cytokine Release Syndrome (CRS), acute GVHD (aGVHD) and chronic GVHD (cGVHD), white blood cell (WBC)

\section{Declarations}

\section{Ethics approval and consent to participate}

The study was approved by the Institutional the First Affiliated Hospital of Soochow University. The patients consented to participate. 


\section{Consent for publication}

Written informed consent for research and publication from the patients was obtained.

\section{Availability of data and materials}

The datasets used and/or analysed during the current study are available from the corresponding author on reasonable request.

\section{Competing interests}

The authors declare that they have no competing interests.

\section{Funding}

Funded by the Jiangsu Provincial Key Medical Center (YXZXA2016002), the Priority Academic Program Development of Jiangsu Higher Education Institutions (PAPD), and National Natural Science Foundation of Jiangsu Province (SBE2018740700), National Natural Science Foundation of Jiangsu Province (Grant No. BK20201168).

\section{Authors' contributions}

Hui-ying Qiu and Su-ning Chen designed and supervised the study. Guo-fa Xu, Xie-bing Bao and Li-min Liu analysed data, wrote the manuscript and prepared the Figs; Man Wang and Jun-dan Xie performed experiments and measurements on samples; Zhi-bo Zhang and Zhao Zeng collected and provided the samples and contributed to manuscript preparation; De-Pei Wu contributed to study design and manuscript preparation.

\section{Acknowledgements}

The authors thank to all members of the study team, the patient and his family.

\section{References}

1. Roberts KG, Reshmi SC, Harvey RC, Chen I, Patel K, Stonerock E, et al. Genomic and outcome analyses of Ph-like ALL in NCl standard-risk patients: a report from the Children's Oncology Group. Blood. 2018;132(8):815-24.

2. Tasian SK, Hurtz C, Wertheim GB, Bailey NG, Lim MS, Harvey RC, et al. High incidence of Philadelphia chromosome-like acute lymphoblastic leukemia in older adults with B-ALL. Leukemia. 2017;31(4):981-4.

3. El FR, Savani B, Mohty M, Aljurf M. Hematopoietic Cell Transplant Consideration for Philadelphia Chromosome-Like Acute Lymphoblastic Leukemia Patients. Biol Blood Marrow Transplant. 2020;26(1):e16-20.

4. Shomali W, Gotlib J. World Health Organization-defined eosinophilic disorders: 2019 update on diagnosis, risk stratification, and management. Am J Hematol. 2019;94(10):1149-67.

5. Roberts KG, Li Y, Payne-Turner D, Harvey RC, Yang YL, Pei D, et al. Targetable kinase-activating lesions in Ph-like acute lymphoblastic leukemia. N Engl J Med. 2014;371(11):1005-15.

6. Fang H, Tang G, Loghavi S, Greipp P, Wang W, Verstovsek S, et al. Systematic use of fluorescence in-situ hybridisation and clinicopathological features in the screening of PDGFRB rearrangements of patients with myeloid/lymphoid neoplasms. Histopathology. 2020;76(7):1042-54.

7. Schwab C, Ryan SL, Chilton L, Elliott A, Murray J, Richardson S, et al. EBF1-PDGFRB fusion in pediatric B-cell precursor acute lymphoblastic leukemia (BCP-ALL): genetic profile and clinical implications. Blood. 2016;127(18):2214-8.

8. Horiuchi M, Yoshida M, Yamasaki K, Sakagami R, Aoyama T, Tatsumi N, et al. Effective treatment with imatinib for acute B-lymphoblastic leukaemia with EBF1-PDGFRB fusion. Ann Hematol. 2020.

9. Kanagal-Shamanna R, Jain P, Takahashi K, Short NJ, Tang G, Issa GC, et al. TP53 mutation does not confer a poor outcome in adult patients with acute lymphoblastic leukemia who are treated with frontline hyper-CVAD-based regimens. Cancer. 2017;123(19):3717-24.

10. Carobolante F, Chiaretti S, Skert C, Bassan R. Practical guidance for the management of acute lymphoblastic leukemia in the adolescent and young adult population. Ther Adv Hematol. 2020;11:2040620720903531.

11. Yang F, Zhang J, Zhang X, Tian M, Wang J, Kang L, et al. Delayed remission following sequential infusion of humanized CD19-and CD22-modified CAR-T cells in a patient with relapsed/refractory acute lymphoblastic leukemia and prior exposure to murine-derived CD19-directed CAR-T cells. Onco Targets Ther. 2019;12:2187-91.

12. Huang H, Zhang L, Jiang Y, Liu S, Jin Z, Chen J, et al. Modified BuCy is an alternative conditioning regimen for lymphoma patients undergoing autologous stem cell transplantation. Ann Hematol. 2019;98(5):1259-66.

13. Chen J, Wang RX, Chen F, Sun AN, Qiu HY, Jin ZM, et al. Combination of a haploidentical SCT with an unrelated cord blood unit: a single-arm prospective study. Bone Marrow Transplant. 2014;49(2):206-11.

14. Liu L, Zhang Y, Jiao W, Zhou H, Wang Q, Qiu H, et al. Combination of haploidentical haematopoietic stem cell transplantation with an unrelated cord-blood unit in patients with severe aplastic anemia: a report of 146 cases. Bone Marrow Transplant. 2020;55(10):2017-25.

15. Dohner H, Estey E, Grimwade D, Amadori S, Appelbaum FR, Buchner T, et al. Diagnosis and management of AML in adults: 2017 ELN recommendations from an international expert panel. Blood. 2017;129(4):424-47. 
16. Lee DW, Santomasso BD, Locke FL, Ghobadi A, Turtle CJ, Brudno JN, et al. ASTCT Consensus Grading for Cytokine Release Syndrome and Neurologic Toxicity Associated with Immune Effector Cells. Biol Blood Marrow Transplant. 2019;25(4):625-38.

17. Przepiorka D, Weisdorf D, Martin P, Klingemann HG, Beatty P, Hows J, et al. 1994 Consensus Conference on Acute GVHD Grading. Bone Marrow Transplant. 1995. 15(6): 825-8.

18. Jagasia MH, Greinix HT, Arora M, Williams KM, Wolff D, Cowen EW, et al. National Institutes of Health Consensus Development Project on Criteria for Clinical Trials in Chronic Graft-versus-Host Disease: I. The 2014 Diagnosis and Staging Working Group report. Biol Blood Marrow Transplant. 2015;21(3):389-401.e1.

19. Ferrara JL, Levine JE, Reddy P, Holler E. Graft-versus-host disease. Lancet. 2009;373(9674):1550-61.

20. Roberts KG, Morin RD, Zhang J, Hirst M, Zhao Y, Su X, et al. Genetic alterations activating kinase and cytokine receptor signaling in high-risk acute lymphoblastic leukemia. Cancer Cell. 2012;22(2):153-66.

21. Heilmann AM, Schrock AB, He J, Nahas M, Curran K, Shukla N, et al. Novel PDGFRB fusions in childhood B-and T-acute lymphoblastic leukemia[J].Leukemia: Official journal of the Leukemia Society of America, Leukemia Research Fund, U.K,2017,31(9):1989-1992.

22. Lengline E, Beldjord K, Dombret H, Soulier J, Boissel N, Clappier E. Successful tyrosine kinase inhibitor therapy in a refractory B-cell precursor acute lymphoblastic leukemia with EBF1-PDGFRB fusion. Haematologica. 2013;98(11):e146-8.

23. Chiaretti S, Messina M, Foa R. BCR/ABL1-like acute lymphoblastic leukemia: How to diagnose and treat. Cancer. 2019;125(2):194-204.

24. Zhang Y, Gao Y, Zhang H, Zhang J, He F, Hnizda A, et al. PDGFRB mutation and tyrosine kinase inhibitor resistance in Ph-like acute lymphoblastic leukemia[J].Blood: The Journal of the American Society of Hematology,2018,131(20):2256-2261.

25. Oya S, Morishige S, Ozawa H, Sasaki K, Semba Y, Yamasaki Y, et al. Beneficial tyrosine kinase inhibitor therapy in a patient with relapsed BCR-ABL1-like acute lymphoblastic leukemia with CCDC88C-PDGFRB fusion. Int J Hematol. 2020.

26. Panagopoulos I, Brunetti M, Stoltenberg M, Strandabø RAU, Staurseth J, Andersen K, et al. Novel GTF2I-PDGFRB and IKZF1-TYW1 fusions in pediatric leukemia with normal karyotype. Exp Hematol Oncol. 2019;8:12.

27. Welsh SJ, Churchman ML, Togni M, Mullighan CG, Hagman J. Deregulation of kinase signaling and lymphoid development in EBF1-PDGFRB ALL leukemogenesis[J].Leukemia: Official journal of the Leukemia Society of America, Leukemia Research Fund, U.K,2018,32(1):38-48.

28. Inaba H, Mullighan CG. Pediatric acute lymphoblastic leukemia. Haematologica. 2020;105(11):2524-39.

29. Soverini S, Bassan R, Lion T. Treatment and monitoring of Philadelphia chromosome-positive leukemia patients: recent advances and remaining challenges. J Hematol Oncol. 2019;12(1):39.

30. El FR, Savani B, Mohty M, Aljurf M. Hematopoietic Cell Transplant Consideration for Philadelphia Chromosome-Like Acute Lymphoblastic Leukemia Patients. Biol Blood Marrow Transplant. 2020;26(1):e16-20.

\section{Figures}

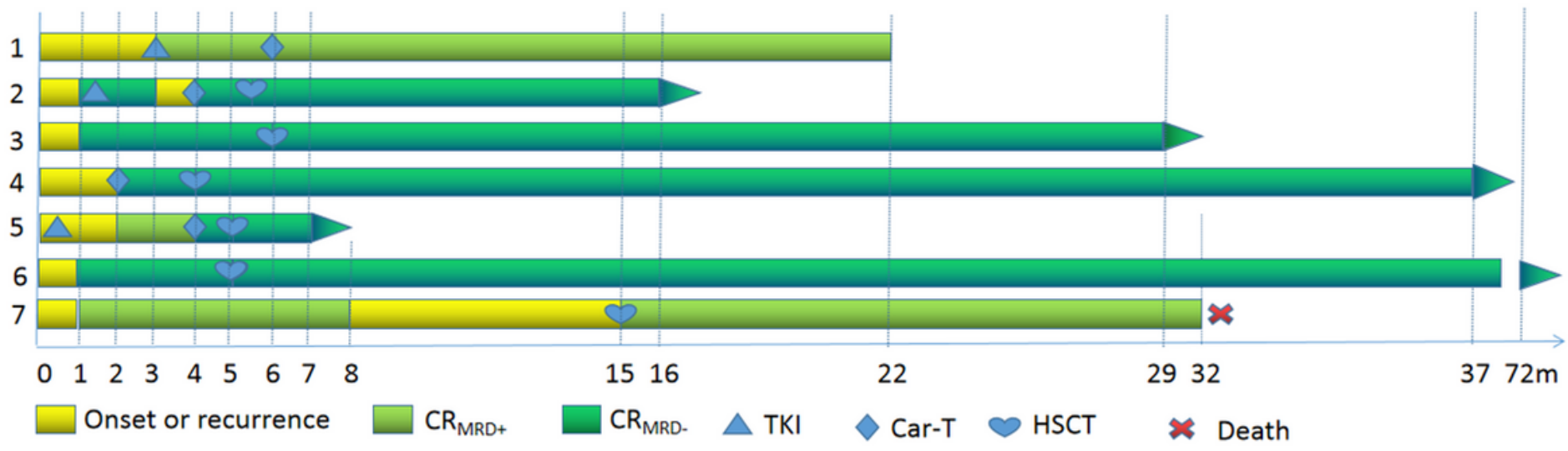

Figure 1

Clinical outcomes of adult B-ALL with PDGFRB fusion 


\section{EFS}

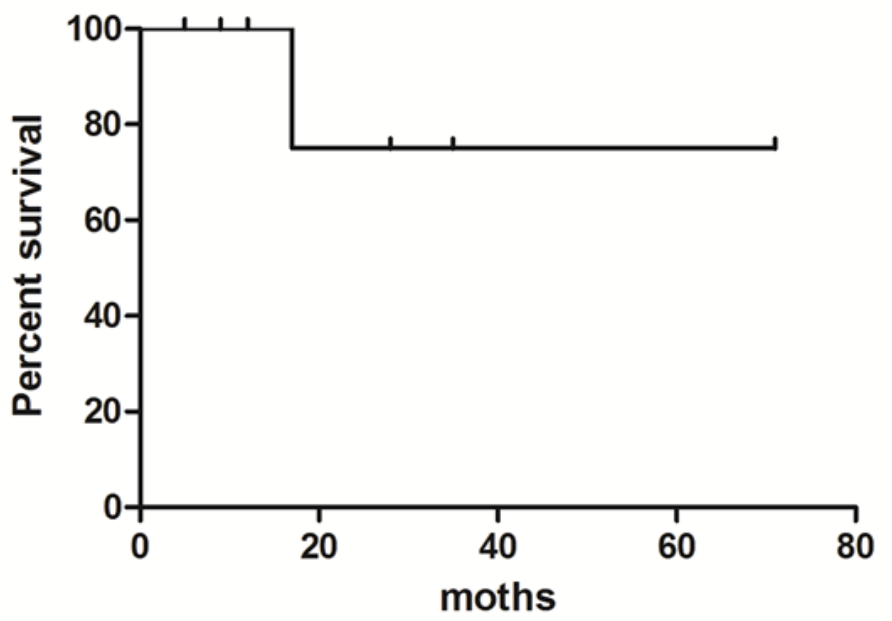

os

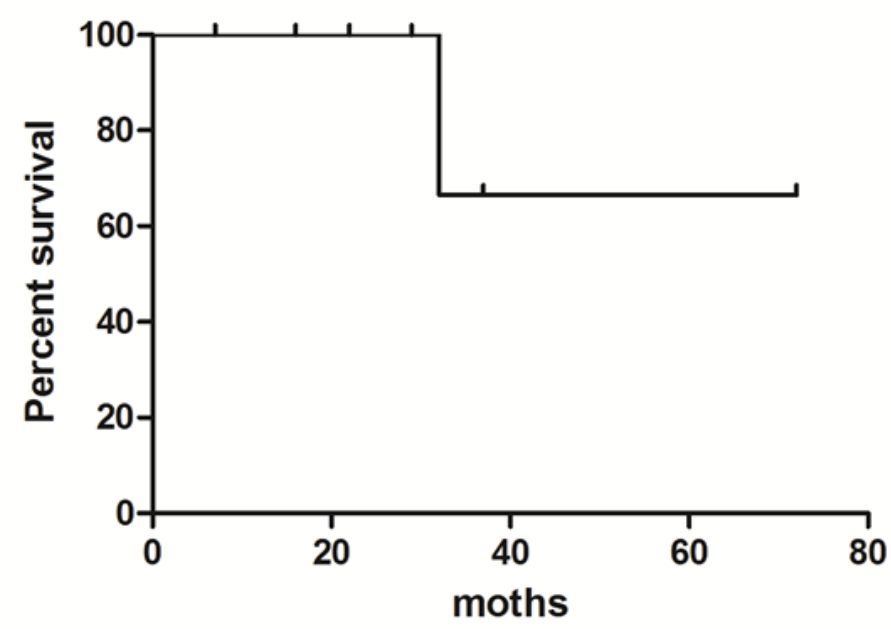

Figure 2

EFS and OS adult of B-ALL with PDGFRB fusion 